\title{
SECRETO PROFESIONAL Y BUENA FAMA EN LA ACCIÓN POLÍTICA
}

\section{Cristóbal Orrego Sánchez}

Profesor de Filosofía Jurídica y Política

Universidad de los Andes

La ética profesional de los políticos se mueve en un difícil equilibrio entre las exigencias de dar a conocer las verdades que afectan al bien común, siendo cada uno veraz y evitando cuidadosamente toda forma de mentira, y las exigencias - no menos importantes - de mantener la debida reserva sobre cuestiones que puedan afectar injustamente la buena fama del prójimo o sobre materias cubiertas por algún deber de secreto profesional. En efecto, si bien es cierto que el escrutinio público de la real valía de los políticos y de sus políticas es un bien deseable para toda forma de gobierno, y mucho más para el régimen democrático participativo, no es menos cierto que, en determinados contextos, puede ser perjudicial para el bien común que todo el mundo pueda enterarse de alguna acción de gobierno real o planeada, o que algunos defectos ocultos de determinadas personas — que no afecten su calidad como gobernante actual o posible - sean ventilados sólo para satisfacer la curiosidad morbosa de quienes nada se ocupan del buen gobierno.

Por eso nos parece de cierto interés recordar algunas ideas clásicas de la ética profesional aplicadas a los políticos profesionales, en relación con los deberes de secreto, por una parte, y de respetar la buena fama, por otra.

\section{El secreto profesional}

La obligación de guardar el secreto también es parte de la veracidad, pues implica custodiar una verdad que sólo algunos tienen derecho a conocer ${ }^{1}$, La confianza se destruye no sólo por la mentira, sino también por la deslealtad en la custodia de los secretos. Este tema es particularmente importante en el ámbito político, donde toda la actividad es pública $y$, sin embargo, existen cuestiones que la misma prudencia y aun la justicia prohíben revelar. A continuación exponemos algunos de los principios universalmente admitidos, con aplicaciones prácticas en el ámbito político.

\footnotetext{
${ }^{1}$ Antonio LANZA, Pietro PALAZZINI: II Principios de Teología Moral. Las Virtudes (Madrid, Rialp, 1958), pp. 469.472.0
} 


\subsection{La obligación de guardar secreto}

La obligación de mantener ocultas determinadas verdades tiene diversas especies. En el ámbito político tienen importancia particular el secreto profesional del político y el secreto de Estado, que son dos especies de secreto comisorio o confiado 2 .

El secreto profesional del político es la obligación que tiene de guardar todas aquellas informaciones que se le hubieren confiado de modo reservado en el ejercicio de su actividad política. Es decir, se le ha confiado una verdad en el contexto de su actuación pública, y se ha establecido un compromiso -implícito o explícito- de no revelar dicha información a nadie. Así, por ejemplo, si dos partidos políticos mantienen conversaciones privadas en preparación de una estrategia política, ninguno de los participantes puede revelar lo que allí se ha tratado o incluso el hecho mismo de haberse realizado la reunión, dependiendo del alcance concreto de la reserva.

Las discusiones al interior de los órganos colegiados de los partidos pueden ser públicas o privadas según lo determinen las mismas normas internas o los acuerdos adoptados para cada caso. Si se establece cierta obligación de reserva, no son lícitas las divulgaciones extraoficiales, ni los comentarios de incidentes o disputas. Esto no constituye una falta de transparencia, sino elemental discreción que la misma prudencia exige para dar unidad a una determinada conducción política. El trabajo político colegiado y el diálogo serían imposibles si los participantes no pudieran gozar de cierta espontaneidad en la discusión de las materias; y dicha espontaneidad o confianza para exponer las opiniones inevitablemente se pierde si todo está sometido a la presión del juicio público. Incluso, se haría más difícil rectificar las propias opiniones. materia.

El secreto de Estado dice relación con la persona que recibe el secreto y con la

La persona debe ser un hombre público, es decir, quien ocupa un cargo público en el gobierno (ministro, parlamentario, asesor técnico de los gobernantes, etc.) o quien desempeña un papel público en relación con las materias que son tratadas por los gobernantes (el presidente de un partido ocupa un cargo que no forma parte de los

\footnotetext{
${ }^{2}$ La obligación de secreto puede tener su fundamento en la ley natural -i.e., en razones válidas por sí mismas aun sin acuerdo previo de las partes- o en la voluntad de los hombres, porque el secreto es un derecho para alguien y como tal puede ser natural o positivo (cfr. S. Th., II-II, q. 57, a. 2). El secreto natural se funda en la misma naturaleza de las cosas, y también tiene lugar en la actividad política: no se pueden revelar los defectos ajenos sin causa justa, por ejemplo. El secreto prometido se funda en la promesa de guardar el secreto hecha después de conocido. El secreto comisorio es aquél que se confia con la condición previa de guardarlo. Este último puede ser simple (confiado a un particular en cuanto tal), profesional (confiado en razón del cargo u oficio del profesional), de Estado (confiado en razón de un cargo público) o de Confesión (sigilo sacramental del sacerdote). Cfr. Antonio ROYO MARÍN, O. P.: I Teología Moral para Seglares. Moral Fundamental y Especial (Madrid, BAC, $5^{2}$ ed.. 1979), p. 623.
} 
organismos estatales o públicos propiamente tales; sin embargo, sus funciones son de repercusión pública, y en relación con ellas puede tener acceso a la discusión de materias propias del gobierno).

En cuanto a la materia, por afectar al bien común debe ser conocida por los gobernantes; ahora bien, el bien común es algo que interesa a todos los miembros de la sociedad, de modo que, en principio, los problemas de gobierno deben llegar al conocimiento de los gobernados, especialmente en un sistema de gobierno democrático, donde la participación pública es o debe ser mayor. Con todo, en muchas ocasiones la información sólo compete a los gobernantes, pues su divulgación pública podría perjudicar a toda la nación (v.gr.: estrategias militares, medidas económicas que no pueden anunciarse anticipadamente, etc.). Quienes tienen acceso a esta información en virtud de su cargo o porque la autoridad les solicita su opinión al respecto, están obligados por el secreto de Estado, de suyo más grave que el profesional.

La necesidad de información sobre la realidad política puede llevar a diversas actuaciones contrarias al secreto, como su injusta averiguación, que atenta normalmente contra la inviolabilidad del hogar o el derecho a la vida privada.

También se viola dicho secreto revelándolo indebidamente o utilizándolo en provecho propio.

\subsection{Excepciones a la obligación de guardar secreto}

La obligación positiva de guardar el secreto profesional no es absoluta, a diferencia de la prohibición absoluta de mentir. En efecto, hay causas que autorizan la revelación de un secreto. Incluso puede llegar a ser obligatorio, pues el secreto no es un derecho absoluto.

Si la revelación del secreto es necesaria para el bien común existe obligación moral de revelarlo, por muy cualificado que sea dicho secreto $^{3}$, supuesto que haya proporción entre la causa que exige la revelación y el mal que se pueda seguir de esa excepción al secreto.

\footnotetext{
${ }^{3}$ Exceptuando el sigilo sacramental que obliga a los sacerdotes respecto de todo lo que en orden a la absolución han conocido al administrar el Sacramento de la Penitencia o Confesión, que no admite excepción alguna. En efecto, la primacia del bien común sobre el bien particular se da cuando los bienes pertenecen al mismo género o nivel de importancia. Por eso, un bien particular de orden superior como la necesidad del secreto en relación a los pecados confesados, que pertenece al orden sobrenatural de los medios para alcanzar el destino eterno, supera y prima sobre el bien común temporal. Por otro lado, la exigencia del sigilo sacramental pertenece al bien común sobrenatural. Naturalmente, esta exigencia de la fe puede ocasionalmente provocar un conflicto entre las exigencias de la autoridad política dirigidas a combatir algunos delitos y los deberes de los sacerdotes, que en conciencia deben negarse a descubrir el secreto, aun a costa de su vida.
} 
En otras palabras, la obligación del secreto cesa, porque prima el bien común sobre bienes particulares del mismo género. Así ocurre cuando se toma conocimiento de una maquinación contra el país, o de un posible atentado terrorista, etc. En estos casos, el político que ha prometido guardar un tal secreto, o al que se le ha confiado por cualquier causa, no debe cumplir su promesa, la cual adolece de objeto ilícito y no vale. Se trata de una aplicación de un principio general de Derecho recogido por el Código Civil. En efecto, para que una persona se obligue a otra por un acto o declaración de voluntad es necesario que recaiga sobre un objeto lícito; y hay un objeto ilícito en todo lo que contraviene al derecho público chileno ${ }^{4}$. No se infringe la lealtad, pues el objeto de dicha virtud sólo puede ser el bien; la lealtad en el mal se llama complicidad o encubrimiento (como se dijo al hablar de la lealtad política).

Para evitar un daño grave al mismo confidente o un daño grave, injusto e irreparable a un tercero, puede ser lícito revelar el secreto natural y prometido. Empero, si tal revelación perjudica también gravemente al confidente, prima su interés sobre el de los terceros.

El secreto profesional es más estricto y no debe revelarse si con ello se causa un grave daño al confidente (como cuando se revela su responsabilidad en un delito), ni aun para salvar a un inocente. En este caso, es el bien común el que exige tal rigor en cuanto al secreto profesional. Lo mismo se aplica al secreto de Estado.

Un político puede revelar el secreto para evitarse un grave perjuicio a sí mismo, salvo que la revelación pueda causar un daño mayor a otra persona o al bien común. Por eso, puede revelarse el secreto natural y el prometido al juez o superior que interroga legítimamente; pero no puede revelarse el secreto profesional, salvo que de no hacerse amenace un mal gravísimo (e incluso en este caso se deberá guardar el secreto, aun a costa de la propia vida, si lo exige el bien común).

En fin, si el mismo confidente divulga el hecho, evidentemente cesa la obligación del secreto.

En definitiva, la política profesional se ve favorecida por el cumplimiento, tanto de la obligación de decir la verdad como de la exigencia de no decirla, sin mentir, en determinados casos que pueden explicarse conforme a las reglas generales ya resumidas. No se trata de que se deba decidir esta cuestión "caso a caso" (v.gr., mirando "las consecuencias"), como si no hubiese reglas generales, sino de que a cada caso se apliquen las reglas generales - algunas de ellas absolutas e inexcepcionablesy se decida lo más virtuoso aunque las consecuencias sean desagradables o difíciles de sobrellevar.

\footnotetext{
${ }^{4}$ Código Civil, arts. 1445 , i. $1^{2}$, № 3; y 1462.
} 
Las virtudes de veracidad, fidelidad o lealtad, sencillez y discreción deben conjugarse prudentemente para producir un ambiente de transparencia y solidaridad en la actividad política. Evidentemente no es igual el grado de lealtad que se debe a los colaboradores que el debido a los contrincantes; pero aun con los adversarios han de observarse las normas mínimas de veracidad que posibilitan una convivencia armónica y una política dialogada.

\section{El respeto al honor y a la buena fama ajena ${ }^{5}$}

La fama y el honor pertenecen al orden de los bienes espirituales externos. En la actividad política tienen particular importancia porque refuerzan la autoridad de quienes gobiernan o pueden llegar a gobernar, y porque es imposible acceder a los cargos públicos, convencer a los electores, influir en las autoridades o ser escuchado seriamente, sin poseer cierto prestigio público. Lo que normalmente se llama "tener una buena imagen" no es otra cosa que tener cierta fama y honor, por más que a veces parezca reducirse el concepto de "buena imagen" a una construcción superficial de los medios de comunicación. El Derecho protege este bien - la buena fama y el honoren la misma Constitución, la cual asegura el respeto y la protección a la vida privada y pública y a la honra de la persona y de su familia ${ }^{6}$.

La fama es la opinión que comúnmente se tiene de una persona; el honor, en cambio, es la testificación que se hace de la excelencia de una persona en presencia del interesado, mediante la alabanza, premios, etc. ${ }^{7}$ Estos bienes son frecuentemente dañados en la lucha política, por cuanto se considera que el bien ajeno es un mal propio. La envidia y el miedo a la derrota en la confrontación política llevan a actos ilícitos que destruyen la fama ajena. En último término, estas actitudes provocan una pérdida generalizada de la buena fama, con lo cual el conjunto de la actividad política se desprestigia. Entonces, no resulta extraño que personas capaces y honradas se nieguen a participar en un ámbito de apariencia tantas veces turbia. El hecho de que se plantee la política como confrontación dialéctica fuerte, especialmente en los términos gobierno vs. oposición, lleva a que la profesión se vea desprestigiada: una mitad se encarga de enlodar a la otra y la suma de dos mitades enlodadas sólo puede dar un conjunto enlodado.

Veamos a continuación algunas de estas conductas.

\footnotetext{
${ }^{5}$ Dominicus M. Prümmer O.P.: Il Manuale Theologiae Moralis (Barcinone, Herder, 1961), pp. 166-179; y ROYO, op. cit, pp. 627 a 645

${ }^{6}$ C.P.R. de 1980 , art. $19 \mathrm{~N}^{2} 4^{\circ}$, i. $1^{2}$

${ }^{7}$ ROYO, op. cit., p. 627.
} 


\subsection{Atentados contra la fama y el honor}

Los atentados más importantes contra la fama ajena son la difamación, la calumnia y la susurración; contra el honor, la injuria y la burla.

a) La difamación y la calumnia

La difamación, es la "denigración de la fama ajena mediante palabras ocultas" Se comete directamente atribuyendo a alguien un defecto, delito o pecado falso: exagerando alguno verdadero; revelando sin justa causa el oculto; o atribuyendo mala intención a una acción buena. Indirectamente se ataca la buena fama negando o disminuyendo las buenas cualidades ajenas, aunque no se impute nada malo; callando cuando se debe alabar; alabando menos de lo que el afectado merece, acompañando críticas que están fuera de lugar ("... es encomiable que...; pero no podemos olvidar...." ); recurriendo a la ironía o a gestos ${ }^{9}$.

Nunca es lícita la calumnia, es decir, la imputación de defectos falsos. En cambio, puede ser lícito revelar defectos ocultos (evitando el odio o animadversión) si hay una causa justa gravemente proporcionada. Así, en política muchas veces el mismo bien común puede exigir que se publiquen (incluso a través de los medios de comunicación social) los defectos de un candidato inmoral que pretende un cargo público. Deben denunciarse los delitos (esta obligación tiene diversa gravedad según las circunstancias del sujeto denunciante; en algunos casos puede ser jurídico-penal). Es lícito comunicar a otros los defectos de un tercero para recibir consejo o para precaver a un inocente contra las maquinaciones, el fraude o el dolo de un político inescrupuloso.

La acción difamadora o calumniosa reviste una gravedad máxima si constituye falso testimonio en juicio ${ }^{10}$.

La fama, es un bien que debe ser custodiado respecto de uno mismo, por lo que sólo con una causa justa y proporcionada será lícito hacer algo que pueda disminuirla. Lo más frecuente, empero, será que un político se vea en la obligación de defender su buena fama; y se trata de una obligación moral en sentido propio, por cuanto ese prestigio es indispensable para el desempeño de su profesión. Sin esa fama no se puede acceder a los cargos de gobierno, ni prestar un servicio eficaz a la sociedad. Además, de la fama de un político depende la de sus colaboradores, la de su partido y la de otras personas vinculadas.

\footnotetext{
${ }^{8}$ S. Th., II-1I, q. 73 , a. 1.

${ }^{9}$ S. Th., II-II, q. 73 , a. 1, ad 3.

${ }^{10}$ S. Th., II-II, q. 70 , a. 4.
} 
Finalmente, recordemos que existe obligación de indemnizar al afectado por una difamación. Esto debe hacerse retractándose en iguales o similares circunstancias (por la prensa, ante los oyentes privados, etc., si de tal modo se difamó) cuando se trata de una calumnia; o compensando la difamación simple (revelación injusta de defectos verdaderos) mediante el reconocimiento de aspectos positivos, la alabanza, etc. Si la difamación tuvo consecuencias económicas, también debe repararse en este aspecto.

Estos deberes de reparación tienen como correlato jurídico el reconocimiento del derecho de rectificación o respuesta.

b) La susurración

La susurración, es toda conducta que tiende a disolver la amistad entre dos personas, sembrando entre ellas la cizaña y la discordia ${ }^{11}$. La susurración atenta no sólo contra la fama ajena, sino contra un bien mayor: la amistad ${ }^{12}$. El intento de separar a dos o más políticos que pueden resultar contrincantes peligrosos es lícito sólo si no se subordina a ese fin la amistad personal existente entre ellos. No es necesario llegar a los ataques personales o a la provocación de animadversiones para desbaratar una alianza política. Evidentemente, si una determinada alianza política resulta en sí misma inmoral no es malo - al contrario: es moralmente meritorio- denunciarla y disolverla, incluso haciendo ver a una de las partes la malicia y los defectos de la otra. Cuando se destruye una amistad fundada en el mal no existe propiamente susurración, sino un acto de caridad. La unión en el mal está más cerca de la complicidad que de la verdadera amistad o lealtad.

c) La injuria y la burla

Se oponen al honor del prójimo presente la injuria y la burla ${ }^{13}$.

La contumelia o injuria, procedente de la ira, puede ser de palabra o de obra. Su objeto es denigrar a alguien presente insultándolo abiertamente. Nunca tiene justificación ${ }^{14}$.

El agredido puede defenderse exigiendo una reparación. Muchas veces es obligatorio defenderse por el bien del propio agresor y de terceros o por el bien común, pues si nadie impide las ofensas es fácil que prosperen ${ }^{15}$. No se debe acudir a medios de

\footnotetext{
${ }^{11}$ ROYO, op. cit., pp. 639-641

12 "Susurro autem intendit amicitiam separare" (S. Th., I1-11, q. 74, a. 1).

${ }^{13}$ ROYO, op. cit, pp. 641-644.

${ }^{14}$ S. Th., II-11, q. 72 , a. 1.

${ }^{15}$ S. Th, 11-11, q. 72, a. 3, resp.
} 
defensa que a su vez sean contumeliosos, dado que podría generarse una virulencia creciente. Lo más perfecto, según las exigencias cristianas de la caridad, sería perdonar de inmediato (si la ofensa afecta sólo al directamente injuriado), aunque, en justicia, nunca se está obligado a ello.

La burla ${ }^{16}$, por su parte, consiste en avergonzar a alguien frente a los demás enrostrándole sus culpas o defectos, reales o supuestos. En materia política esta actitud casi nunca aparece por pura broma o juego; usualmente implica cierto desprecio. Nunca es lícito burlarse de otro, aunque puede serlo presentar sus defectos de manera objetiva, por exigirlo el bien común. Esto no significa que en política sea inmoral acudir a la ironía como técnica oratoria, pues siempre es posible una ironía elegante, referida a las materias y argumentos que se tratan y no a los defectos de las personas involucradas.

\footnotetext{
${ }^{16}$ S. Th., II-II, q. 76 , a.. 1 y 2.
} 